\title{
Biodiesel production from non-edible Mahogany seed oil by dual step process and study of its oxidation stability
}

\author{
S. M. S. Rana ${ }^{1}$, M. A. Haque ${ }^{1}$, S. Poddar ${ }^{2}$, S. M. A. Sujan ${ }^{2}$, M. Hossain ${ }^{2}$ and M. S. Jamal ${ }^{2 *}$ \\ ${ }^{1}$ Department of Chemistry, Jagannath University, Bangladesh. \\ ${ }^{2}$ Institute of Fuel Research and Development (IFRD), BCSIR, Dhaka, Bangladesh.
}

\begin{abstract}
Biodiesel derived from non edible sources is a potential eco-friendly substitute to petroleum fuel. Acid-catalysed esterification was applied to reduce free fatty acid (FFA) content of oil to zero followed by base-catalyzed transesterification to convert esterified product to its mono-esters and glycerol. The major factors affecting the conversion efficiency of these two processes such as amounts of solvent and catalyst, reaction temperature, and reaction time were optimized. The physical properties and heating value of Mahogany Seed Oil (MSO) and MSO diesel are evaluated and compared with that of commercial diesel. FTIR and 1H NMR spectrum of MSO and MSO biodiesel confirmed the conversion of MSO to biodiesel. The oxidation stability of MSO biodiesel oil was also studied. The study affirms the production of biodiesel from MSO as a renewable alternative to the diesel fuel.
\end{abstract}

Keywords: Biodiesel; Mahogany seed oil; Free Fatty Acid; Trans-esterification; Anti-oxidant

\section{Introduction}

The rapidly increasing prices and uncertainties concerning petroleum availability, a growing concern of the environment and the effect of greenhouse gases during the last decades, has revived more and more interests in the use of vegetable oils as a substitute of fossil fuel (Balat and Balat, 2008) Vegetable oils have long been promoted as possible alternatives of diesel. Besides animal fats, used cooking oil can be used to produce biodiesel which can be a good alternative to petroleum-based fuels. Vegetable oils are widely available from various sources, and the glycerides present in the oils can be considered as a viable alternative for diesel fuel (Balat and Balat, 2008). Depending upon the climate and soil conditions, different countries are looking for different types of vegetable oils as substitutes for diesel fuels. For example, soybean oil in South-east Asia (mainly Malaysia and Indonesia) and coconut oil in Philippines are being considered as raw materials for biodiesel. Biodiesel is receiving increased attention as a non-toxic, biodegradable, and renewable diesel fuel. Use of vegetable oil in diesel engines is not a radically new concept (Agarwal and Das, 2001; Recep et al., 2001). It received attention only recently when it was conclusively realized that petroleum fuels are dwindling fast and environment- friendly renewable substitutes must be identified (Sahoo et al., 2007). Several researchers have reported on the production of biodiesel from different seed oil (Canakci and Gerpan, 1999; Encinar et al., 2002; Pilar et al., 2004).
Transesterification is the chemical reaction between triglycerides and alcohol in the presence of catalyst to produce mono-esters (Sinha et al., 2008; Xu et al., 2007). Most of the biodiesel produced worldwide is based on transesterification in homogeneous media with sodium methoxide as the reaction catalyst. The main difficulty for the production of biodiesel from vegetable oil is its high free fatty acid content. To reduce FFA, different pretreatment methods were applied previously. Among them steam distillation, utilization of solid base catalyst, extraction by alcohol and acid catalyst esterification were investigated (Morshed et al., 2011; Xu et al., 2007). Comparing different aforementioned pretreatment methods, acid catalyst esterification is preferable one. Solid acid catalyst offers some advantages but the reaction rate is slow (Leung et al., 2010). Steam distillation is also not viable for high temperature operation. For the low solubility of FFA in alcohol, the alcohol extraction process is an expensive method (Morshed et al., 2011).

The presence of high levels of unsaturation in fatty acid methyl esters (FAME) makes biodiesel very susceptible to oxidation as compared to petroleum diesel (Domingos et al., 2007). The degree of unsaturation of MSO is very low. Oleic acid is the only unsaturated fatty acid in the composition of MSO and its relative percentage is less than 1\% (Majid et al.,

\footnotetext{
*Corresponding author: E-mail:msjdubd@gmail.com
} 
2004). Oxidative processes bring about increased viscosity as a result of condensation reactions involving double bonds, also leading to the formation of insoluble's, which can potentially plug fuel filters and injection systems (Monyem and Van, 2001). The increased acidity and increased peroxide value as a result of oxidation reactions can also cause the corrosion of fuel system components, hardening of rubber components, and fusion of moving components (Monyem and Van, 2001; Tao, 1995). To combat such problems, oxidation stability study is important.

The mahogany tree grows everywhere in Bangladesh. So the production of biodiesel from mahogany seed oil will be economical for the future energy consumption. The objective of this research work was to optimize the reaction condition for the production of biodiesel from mahogany seeds oil and study the oxidation stability of produced biodiesel. The properties of the MSO and MSO biodiesel such as viscosity, pour point, flash point, density and heating value are measured. According to our literature survey, this is the first approach in Bangladesh for the production of biodiesel from Mahogany (Swietenia macrophylla) seed.

\section{Materials and methods}

\section{Materials}

Mahogany (Swietenia macrophylla) seeds were used as raw material to produce biodiesel. The seeds were collected from Pirojpur and Jamalpur districts of Bangladesh. 99.8\% Methanol was used in esterification and trans- esterification. $\mathrm{NaOH}$ and $\mathrm{H}_{2} \mathrm{SO}_{4}$ used as catalyst were purchased from Active Fine Chemicals Ltd., Bangladesh. AR grade solvents such as ethanol, diethyl ether, and n-hexane were used.

\section{Extraction of oil}

Crude MSO was extracted from Mahogany seeds ( $80 \mathrm{gm}$ ) by Soxhlet extraction for 30 minutes, using n-hexane as solvent. The Mahogany seeds were taken in the tube shaped filter paper which was placed into the Soxhlet with the powder of seeds and hot extraction of oil was done.

\section{Experimental procedure}

Fatty acid methyl ester (FAME) was prepared using two step reactions.

\section{Acid-catalyzed esterification}

The main objective of acid-catalysed esterification was to reduce the acid value of oils. In this step at first catalyst $\left(\mathrm{H}_{2} \mathrm{SO}_{4}\right)$ was mixed with methanol using an agitator. Then the mixture of alcohol and catalyst was charged into a closed three-neck round-bottom flask with raw MSO. Reaction conditions selected for this optimization were $60{ }^{\circ} \mathrm{C}$ temperature, $400 \mathrm{rpm}$ agitation rate and time of $90 \mathrm{~min}$. After that, the treated oil was allowed to settle for at least $1 \mathrm{~h}$ in a separating funnel and the treated oil was collected as bottom layer.

\section{Base catalyst transesterification}

The base catalyst $(\mathrm{NaOH})$ was added into methanol and was stirred until dissolved in the methanol under slight warm condition. Then the pretreated oil was added into the mixture. Reaction was carried out in apparently closed system to prevent the loss of methanol. The reaction mixture was kept below $65^{\circ} \mathrm{C}$ (boiling point the methanol) at atmospheric pressure. The reaction time was varied from 30 to $120 \mathrm{~min}$. The mixture was then allowed to settle overnight before separation of the glycerol layer to get FAME on the top. After separation of biodiesel, it was purified, dried and finally stored.

\section{Analytical method}

\section{FTIR analysis}

FTIR of the MSO and MSO biodiesel were conducted using iRAffinity-1 spectrophotometer, SHIMADZU, Japan in the range of 500-4000 $\mathrm{cm}^{-1}$. The liquid sample was directly used for the analysis.

\section{Elemental analysis}

Elemental analysis was done by organic elemental analyzer (Reactor temp. $900{ }^{\circ} \mathrm{C}$, He: $250 \mathrm{kPa}, \mathrm{O}_{2}: 250 \mathrm{kPa}$, TCD, Flash 2000, Thermo Scientific, USA). This instrument analyzes in accordance with the procedures stated in ASTM Standard D 5291-02.

\section{${ }^{1} H$ NMR analysis}

The ${ }^{1} \mathrm{H}$ NMR spectra were recorded on a BRUKER, AVANCE-III 400 MHz FT-NMR instrument, with chemical shift data reported in ppm relative to the solvent used. The spectra were taken by usingCDCl${ }_{3}$ solvent.

\section{TGA analysis}

TG-DTA 6300 (Exstar 6000), Seiko Instrument Incorporation, Japan was used for thermal stability analysis.

\section{Oxidation stability analysis}

The Rancimat 743 (Metrohm, Switzerland) was used to determine the oxidative stability of biodiesel in accordance with the EN14112. Analysis condition: Temperature $110^{\circ} \mathrm{C}$, 
Delta T 1.5 , air flow rate $10 \mathrm{~L} / \mathrm{h}$. The amount of sample and water used were $3 \mathrm{gm}$ and $60 \mathrm{ml}$ respectively. TertButyl hydroquinone (TBHQ), Propyl-3,4,5-trihydroxy benzoate (PG) and Butyl hydroxyl anisol (BHA) were utilized as antioxidant for this experiment.

\section{Result and discussion}

Extraction of oil

Solvent extraction process used to extract the oil from Mahogany seeds. A commonly used solvent, n- hexane was used to carry out the experiment. About $52.08 \%$ oil can be extracted from Mahogany seeds.

Table I. Variation of (a) methanol-to-oil ratio, (b) acid catalyst-to-oil ratio, (c) temperature and (d) time for the reduction of acid value and FFA

\begin{tabular}{|c|c|c|c|c|c|c|}
\hline Id & Oil :MeOH & Oil : Catalyst & Temp. $\left({ }^{\circ} \mathrm{C}\right)$ & Time (min) & Acid value (mg KOH/g) & $\operatorname{FFA}(\%)$ \\
\hline \multirow{5}{*}{$\mathrm{a}$} & $30: 09$ & $30: 0.36$ & 60 & 100 & 4.57 & 2.29 \\
\hline & $30: 12$ & $30: 0.36$ & 60 & 100 & 3.62 & 1.81 \\
\hline & $30: 15$ & $30: 0.36$ & 60 & 100 & 0.91 & 0.46 \\
\hline & $30: 18$ & $30: 0.36$ & 60 & 100 & 0.89 & 0.45 \\
\hline & $30: 21$ & $30: 0.36$ & 60 & 100 & 0.00 & 0.00 \\
\hline \multirow{4}{*}{$\mathrm{b}$} & $30: 21$ & $30: 0.27$ & 60 & 100 & 1.80 & 0.90 \\
\hline & $30: 21$ & $30: 0.36$ & 60 & 100 & 0.90 & 0.45 \\
\hline & $30: 21$ & $30: 0.45$ & 60 & 100 & 0.50 & 0.25 \\
\hline & $30: 21$ & $30: 0.54$ & 60 & 100 & 0.00 & 0.00 \\
\hline \multirow{5}{*}{$\mathrm{c}$} & $30: 21$ & $30: 0.54$ & 30 & 100 & 1.50 & 0.75 \\
\hline & $30: 21$ & $30: 0.54$ & 40 & 100 & 0.90 & 0.45 \\
\hline & $30: 21$ & $30: 0.54$ & 50 & 100 & 0.30 & 0.15 \\
\hline & $30: 21$ & $30: 0.54$ & 60 & 100 & 0.00 & 0.00 \\
\hline & $30: 21$ & $30: 0.54$ & 70 & 100 & 0.20 & 0.10 \\
\hline \multirow{5}{*}{$\mathrm{d}$} & $30: 21$ & $30: 0.54$ & 60 & 45 & 1.60 & 0.80 \\
\hline & $30: 21$ & $30: 0.54$ & 60 & 60 & 1.20 & 0.60 \\
\hline & $30: 21$ & $30: 0.54$ & 60 & 75 & 0.7 & 0.35 \\
\hline & $30: 21$ & $30: 0.54$ & 60 & 90 & 0.0 & 0.00 \\
\hline & $30: 21$ & $30: 0.54$ & 60 & 105 & 0.3 & 0.15 \\
\hline
\end{tabular}


Table II. Variation of (a) methanol-to-oil ratios, (b) base catalyst-to-oil ratios, (c) temperature, (d) time for the production of biodiesel

\begin{tabular}{|c|c|c|c|c|c|c|}
\hline Id & Oil : $\mathrm{MeOH}$ & Oil : Catalyst & Tem. $\left({ }^{\circ} \mathrm{C}\right)$ & Time (min) & Yield\%(Biodiesel) & Yield $\%$ (Glycerin) \\
\hline \multirow{5}{*}{$\mathrm{a}$} & $10: 3$ & $10: 0.07$ & 60 & 120 & 65.53 & 34.94 \\
\hline & $10: 4$ & $10: 0.07$ & 60 & 120 & 85.72 & 14.28 \\
\hline & $10: 5$ & $10: 0.07$ & 60 & 120 & 92.67 & 07.33 \\
\hline & $10: 6$ & $10: 0.07$ & 60 & 120 & 90.05 & 09.95 \\
\hline & $10: 7$ & $10: 0.07$ & 60 & 120 & 80.23 & 19.77 \\
\hline \multirow{4}{*}{$\mathrm{b}$} & $10: 5$ & $10: 0.05$ & 60 & 120 & 85.75 & 14.25 \\
\hline & $10: 5$ & $10: 0.07$ & 60 & 120 & 88.20 & 11.80 \\
\hline & $10: 5$ & $10: 0.09$ & 60 & 120 & 95.21 & 04.79 \\
\hline & $10: 5$ & $10: 0.11$ & 60 & 120 & 74.27 & 25.73 \\
\hline \multirow{5}{*}{$\mathrm{c}$} & $10: 5$ & $10: 0.09$ & 40 & 120 & 75.04 & 24.96 \\
\hline & $10: 5$ & $10: 0.09$ & 50 & 120 & 84.44 & 15.56 \\
\hline & $10: 5$ & $10: 0.09$ & 60 & 120 & 89.31 & 10.69 \\
\hline & $10: 5$ & $10: 0.09$ & 70 & 120 & 84.45 & 15.55 \\
\hline & $10: 5$ & $10: 0.09$ & 80 & 120 & 74.13 & 25.87 \\
\hline \multirow{4}{*}{$\mathrm{d}$} & $10: 5$ & $10: 0.09$ & 60 & 30 & 86.67 & 13.33 \\
\hline & $10: 5$ & $10: 0.09$ & 60 & 60 & 93.67 & 06.33 \\
\hline & $10: 5$ & $10: 0.09$ & 60 & 90 & 97.34 & 02.66 \\
\hline & $10: 5$ & $10: 0.09$ & 60 & 120 & 69.10 & 30.90 \\
\hline
\end{tabular}

\section{Acid catalyzed esterification}

To reduce the acid value of MSO, the acid catalyst esterification was done. To meet the optimum condition, different variables such as methanol to oil ratio, catalyst to oil ratio, reaction time and temperature were optimized which are shown in Table 2. At the conditions of 100 min of reaction time at $60^{\circ} \mathrm{C}$, acid value and FFA were decreased gradually with the increase of methanol percentage in the oil to methanol ratio and met to 0.00 at ratio of 30:21. Then acid catalyst was also varied as a result of which acid value decreased to the optimum range. At the same way the other variables were also varied and optimum conditions were fixed. The optimum reaction condition thus found was 30:21 of oil to methanol ratio; 30:0.54 of oil to catalyst ratio and reaction time of 60 mins at a temperature of $60^{\circ} \mathrm{C}$ with moderate stirring. 


\section{Base catalyzed transesterification}

To maximize the biodiesel yield, base catalyst transesterification was optimized. For this different variables such as reaction between oil and methanol to form sodium methoxide does not proceed efficiently. In addition, 97.34\% biodiesel yield was observed for 90 mins reaction time while keeping

Table III. Proximate physico-chemical properties of MSO, Jatropha, C. inophyllum Biodiesel with standard biodiesel and Petro-diesel

\begin{tabular}{|c|c|c|c|c|c|c|}
\hline $\begin{array}{l}\text { Name of the } \\
\text { Parameter }\end{array}$ & Method & $\begin{array}{l}\text { MSO } \\
\text { Diesel }\end{array}$ & $\begin{array}{l}\text { Biodiesel } \\
\text { Standard }^{a}\end{array}$ & $\begin{array}{c}\text { Jatropha } \\
\text { Biodiesel }^{b}\end{array}$ & $\begin{array}{l}\text { C. inophyllum } \\
\text { Biodiesel }^{c}\end{array}$ & Diesel $^{c}$ \\
\hline Color index & D $1500-64$ & 0.5 & - & - & - & - \\
\hline Density at $15^{\circ} \mathrm{C}, \mathrm{g} / \mathrm{cc}$ & IP-160/57 & 0.88 & - & 0.88 & 0.87 & - \\
\hline Kinematic viscosity, & D $445-65\left(40^{\circ} \mathrm{C}\right)$ & 4.18 & $1.9-6.0$ & 4.8 & 4.0 & $1.3-4.1$ \\
\hline $\mathrm{cSt}$ & D $445-65\left(100^{\circ} \mathrm{C}\right)$ & 4.16 & - & - & - & - \\
\hline Pour point, ${ }^{\circ} \mathrm{C}$ & D $97-57$ & 7.0 & -15 to 10 & 2 & 4.3 & -35 to -15 \\
\hline Flash point, ${ }^{\circ} \mathrm{C}$ & D $93-62$ & 120 & $100-170$ & 135 & 140 & $60-80$ \\
\hline Acid value, $\mathrm{mg} \mathrm{KOH} / \mathrm{g}$ & IP $1 / 58$ & 0.02 & $>0.08$ & 0.4 & 1.62 & - \\
\hline Water content, $\%$ & IP-74/57 & Nil & $0.05 \%$ & 0.025 & 0.005 & 0.016 \\
\hline Ash content, \% & D 482-63 & 0.02 & - & 0.012 & - & - \\
\hline Carbon residue, wt $\%$ & D $189-65$ & 0.34 & - & 0.2 & - & - \\
\hline $\begin{array}{l}\text { Heating value, } \\
\mathrm{MJ} / \mathrm{Kg}\end{array}$ & IP- $12 / 58$ & 40.13 & - & 39.230 & 41.397 & - \\
\hline
\end{tabular}

$\mathrm{a}$ (Leung et al. 2010), b (Ong et al., 2011), c (Joshi and Pegg, 2007)

Table IV. The elemental analysis of MSO biodiesel

\begin{tabular}{cccccc}
\hline Sample & N (\%) & C (\%) & H (\%) & S (\%) & O (\%) \\
\hline MSO biodiesel & 0.00 & 73.94 & 11.46 & 0.00 & 14.60 \\
\hline
\end{tabular}

methanol to oil ratio, catalyst to oil ratio, reaction time and temperature were considered which are shown in Table 3. As oil to methanol ratio was increased, the production of biodiesel was also increased and reached maximum yield (92.67\%) at the oil to methanol of $10: 5$. In case of oil to catalyst ratio, maximum yield of $95.21 \%$ was observed at 10:0.09. At the same way the other variables were also varied and optimum condition were fixed. When temperature was employed above $60^{\circ} \mathrm{C}$ during transesterification reaction, biodiesel production was seen to decrease. Since methanol's boiling point is $63.7^{\circ} \mathrm{C}$, at temperature higher than $60^{\circ} \mathrm{C}$ other variables at their optimum levels. The optimum condition for transesterification was 10:05:0.09 of oil to methanol to catalyst ratio and reaction time of $90 \mathrm{mins}$ at a temperature of $60^{\circ} \mathrm{C}$ with moderate stirring.

\section{Physico-chemical properties of MSO and MSO Biodiesel}

The physic-chemical properties of MSO biodiesel was measured according to procedures mentioned in Table III. In conjunction, their values were also compared with that of biodiesel standard (Leung et al. 2010), Jatropha biodiesel (Ong et al. 2011), and C. inophyllum biodiesel and diesel (Joshi and peg, 2007). Kinetic viscosity, pour and flash point, and acid value of MSO biodiesel are well comparable with biodiesel standard as well as other two biodiesels. An exclusive property of MSO biodiesel is its water content, water content was found to be zero in biodiesel derived from Mahogany. Heating value and density (at $15^{\circ} \mathrm{C}$ ) show little deviation from biodiesel obtained from Jatropha and $\mathrm{C}$. 


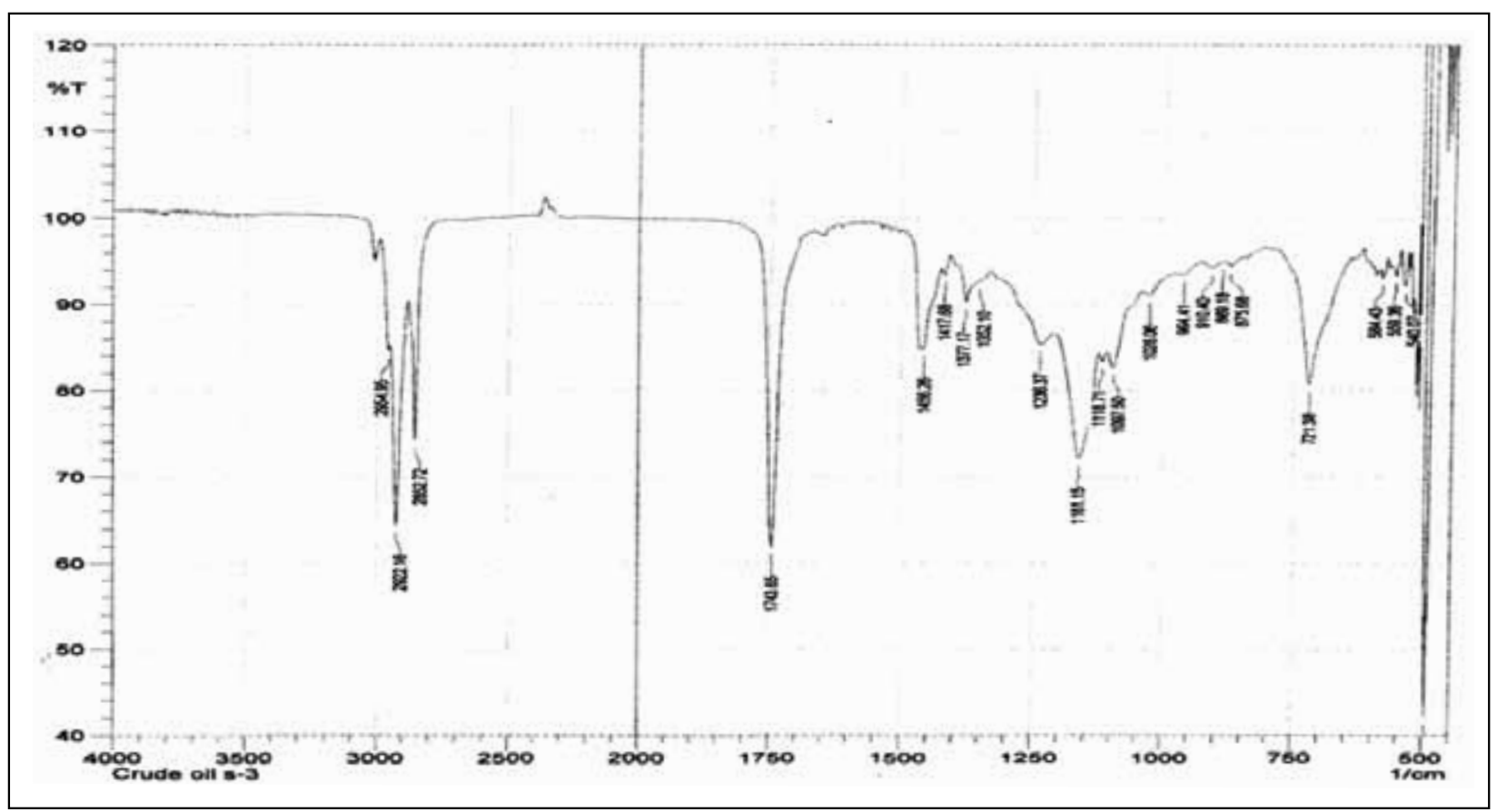

Fig. 1(a). FTIR spectra of crude mahogany seeds oil

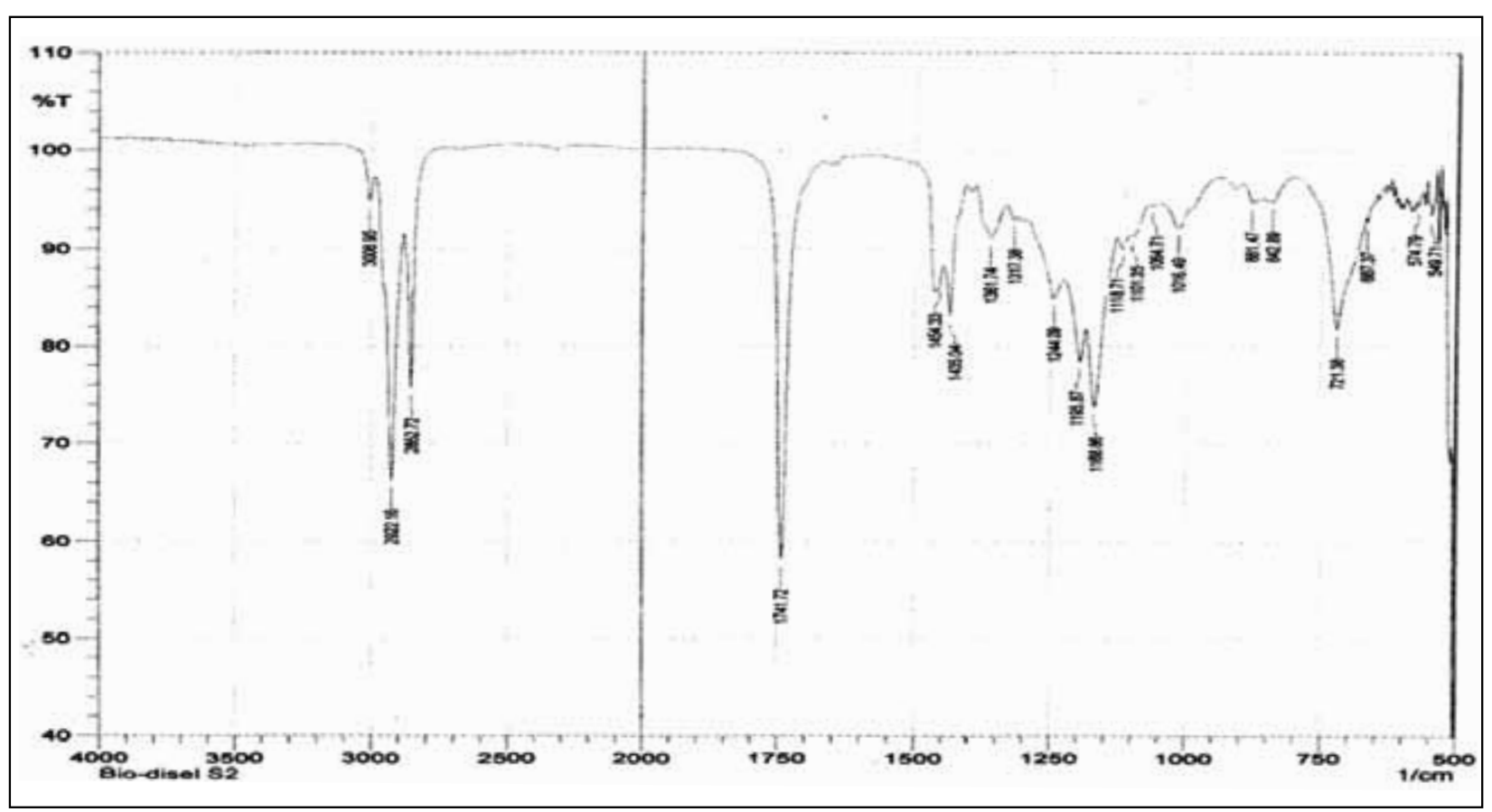

Fig. 1(b). FTIR spectra of mahogany seeds oil biodiesel

inophyllum. Carbon residue of MSO biodiesel is also found to be analogous with that of Jatropha biodiesel. I addition, kinetic viscosity at $40{ }^{\circ} \mathrm{C}$ of MSO biodiesel is within the range of diesel standard.
FTIR analysis

FTIR showing the main peaks of the MSO at $1743 \mathrm{~cm}^{-1}$ for the ester carbonyl $(>\mathrm{C}=\mathrm{O})$ groups (Fig. 1a) and for MSO 
biodiesel carbonyl peak appeared $1741 \mathrm{~cm}^{-1}$ (Sylvester et al., 2013). The most characteristics peak for FAME appeared at $1435 \mathrm{~cm}^{-1}$ which represents methoxy $\left(\mathrm{CH}_{3}-\mathrm{O}\right)$ group (Fig. 1b)
(Sylvester et al., 2013). $\mathrm{C}=\mathrm{C}$ double bonds absorption band appeared in the region 1435-1454 $\mathrm{cm}^{-1}$ (Sylvester et al., 2013).

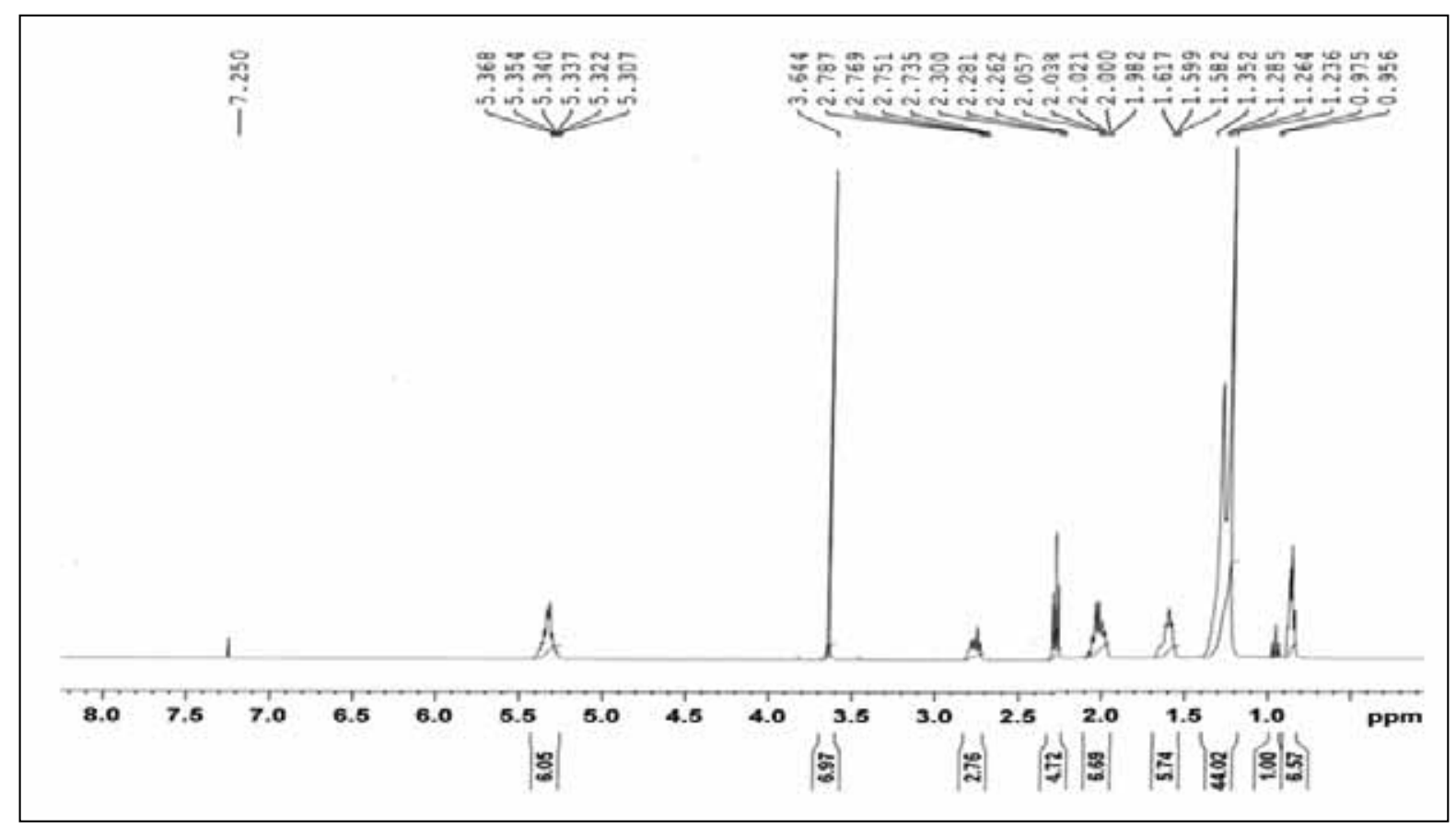

Fig. 2. Proton NMR of the MSO biodiesel

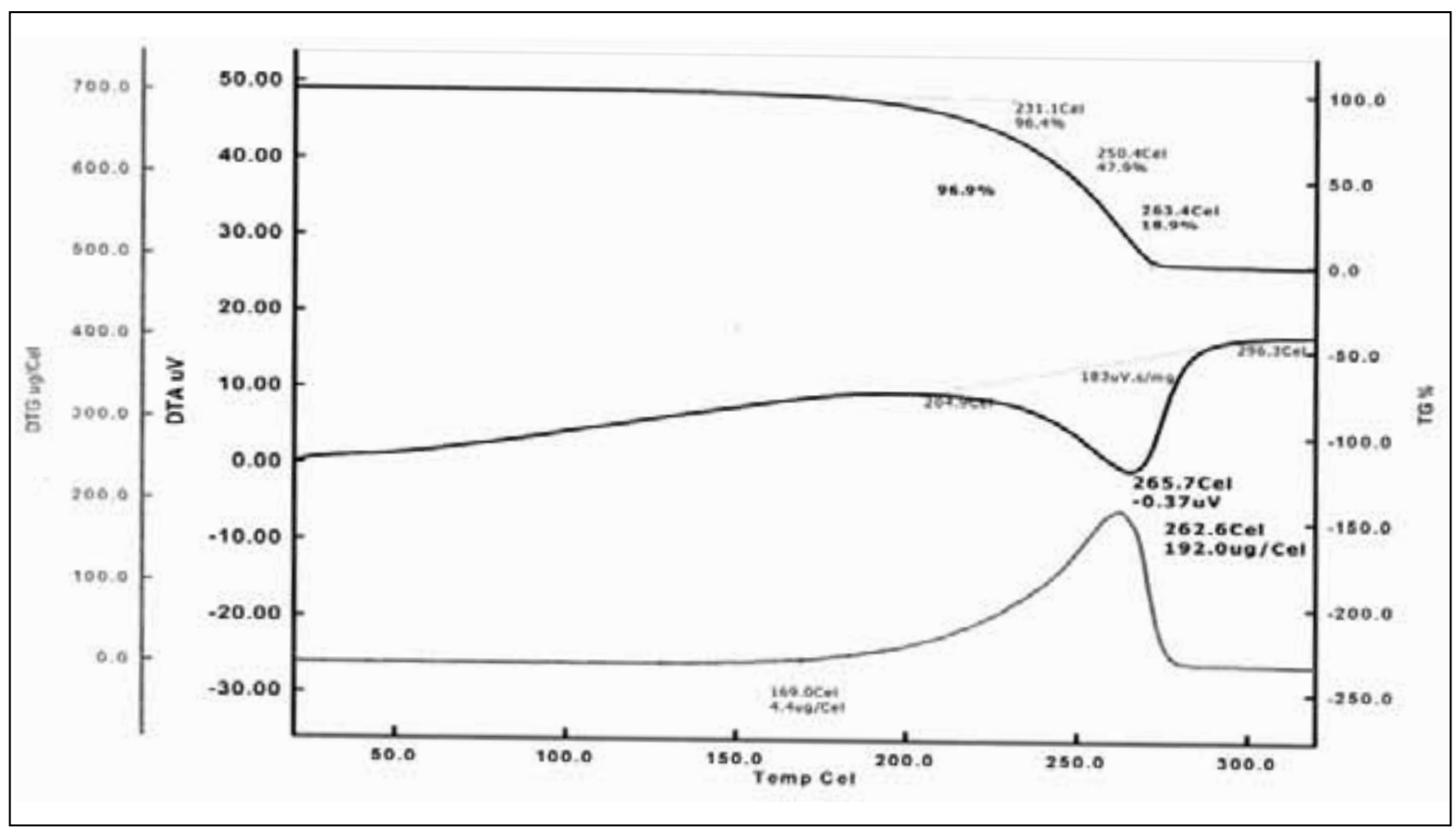

Fig. 3. Thermogravimetric curves of MSO biodiesel 


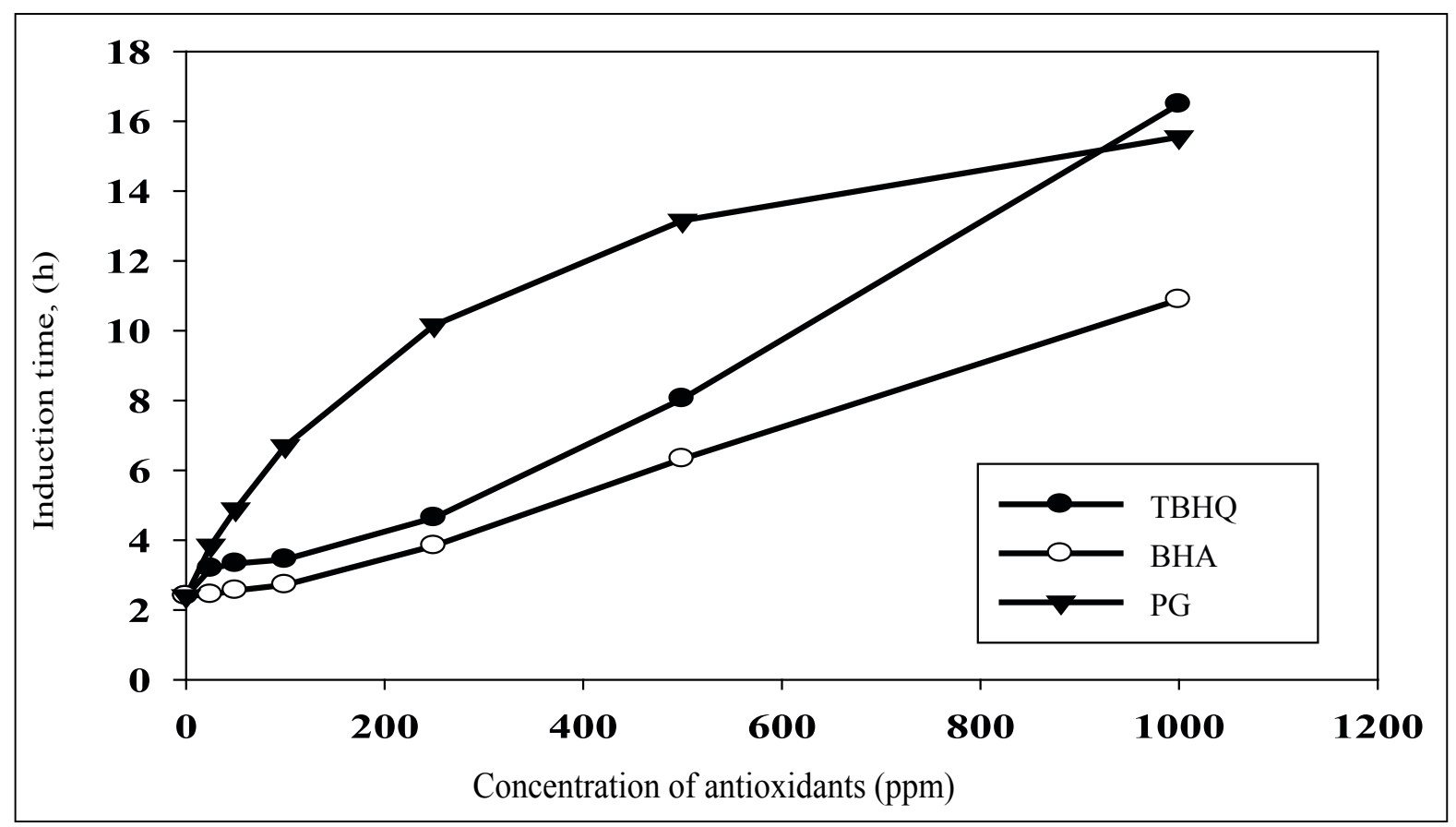

Fig. 4. Oxidation stability test by using phenolic antioxidant

\section{Elemental analysis}

The absence of sulphur and nitrogen in MSO biodiesel indicates it is to be an environmentally benign fuel (Table 4). As obtained in elemental analysis, carbon, hydrogen and oxygen presents were $73.94 \%, 11.46 \%$ and $14.60 \%$ respectively. This analysis leads to the empirical formula of MSO biodiesel as $\mathrm{C}_{7} \mathrm{H}_{13} \mathrm{O}$.

\section{Proton NMR analysis}

The ${ }^{1} \mathrm{H}$ NMR spectrum of MSO biodiesel is shown in Fig-2. The multiplet at $\delta 5.31-5.36 \mathrm{ppm}$ represents the olefinic protons $(-\mathrm{CH}=\mathrm{CH}-)$. A singlet at $\delta 3.65 \mathrm{ppm}$ is representing methoxy protons of the ester functionality of the biodiesel. The bis-allylic proton signal of polyunsaturated fatty acid (like linoleic acid) generally appears around at $\delta 2.8 \mathrm{ppm}$. So, the multiplet at $\delta 2.76 \mathrm{ppm}$ indicates the bis-allylic protons $\left(-\mathrm{C}=\mathrm{HC}-\mathrm{CH}_{2}-\mathrm{CH}=\mathrm{C}-\right)$ of the unsaturated fatty acid chain. The triplet at $\delta 2.26-2.30 \mathrm{ppm}$ represents the $\alpha$-methylene protons of ester $\left(-\mathrm{CH}_{2}-\mathrm{CO}_{2} \mathrm{Me}\right)$. The $\alpha$-methylene protons of double bond $\left(-\mathrm{CH}_{2}-\mathrm{C}=\mathrm{C}\right.$-) and $\beta$-methylene protons of ester $\left(\mathrm{CH}_{2}-\mathrm{C}\right.$ $\left.\mathrm{CO}_{2} \mathrm{Me}\right)$ are both appear as multiplet at $\delta 1.99-2.05 \mathrm{ppm}$ and $\delta$ 1.59-1.62 ppm respectively. The terminal methyl protons at $\delta$ 0.95-0.97 ppm appear as multiplet. The singlet at $\delta 3.65$ ppm indicates the methoxy protons of the ester which is the evidence of conversion of biodiesel from mahogany oil.

\section{TGA analysis of MSO biodiesel}

TGA curves of biodiesel showed three steps, where the first weight loss started to decrease at approximately $231.1^{\circ} \mathrm{C}$ that attributed to a boiling point of biodiesel, the second one started to decrease at $250.4^{\circ} \mathrm{C}$ and it was attributed to boiling point of the esters with unsaturated bonding, and the third step started to decrease at $263.4^{\circ} \mathrm{C}$, and it may be due to some Mahogany oil that was not transesterified (Fig. 3).

\section{Oxidation stability}

Fig. 4, shows that oxidation stability as induction period (IP) increased distinctly of FAME with the addition of phenolic antioxidants than blank FAME (IP = $2.4 \mathrm{~h}$ ). BHA shows 6.0 $\mathrm{h}$ and $10.9 \mathrm{~h}$ oxidation stability at the concentration $500 \mathrm{ppm}$ and 1000 ppm respectively which is met the EN and WWFC biodiesel standard. TBHQ shows better performance than BHA because TBHQ has two hydroxyl groups present in aromatic ring where as one hydroxyl group in BHA. $6.0 \mathrm{~h}$ oxidation stability reached in $350 \mathrm{ppm}$ TBHQ concentration. 
Especially, the addition of PG is very effective for improvement of oxidation stability in the lower concentration due to three hydroxyl group in the aromatic ring. PG achieved 6.0 hand $10.0 \mathrm{~h}$ oxidation stability as IP in the concentration 78 ppm and $240 \mathrm{ppm}$, respectively, which can easily met desired IP according to EN and WWFC standard. $16.49 \mathrm{~h} \mathrm{IP}$ is shown by TBHQ in $1000 \mathrm{ppm}$ concentration which is higher than BHA and PG in the same antioxidant concentration. In the higher concentration, TBHQ showed better results than BHA and PG. Because TBHQ contains two hydroxyl groups and only one tert-butyl group so there less steric hindrance was occurred than PG and BHA.

\section{Conclusion}

In this research work, by solvent extraction $52 \%$ oil was extracted from Mahogany seed. By comparing with other non-edible sources, the oil content is high. The FFA content of MSO is $3 \%$ which makes the pretreatment process easier for the reduction of acid value. The optimum conditions for transesterification reaction were oil to methanol and oil to catalyst $(\mathrm{NaOH})$ of 10:5 and 10:0.09 respectively; reaction time of $90 \mathrm{~min}$ at a temperature of $60{ }^{\circ} \mathrm{C}$ with moderate stirring. About $89-97 \%$ biodiesel was seen to produce in these conditions. The physic-chemical properties of MSO biodiesel are comparable with that of standard diesel and biodiesel. The conversion of MSO to MSO biodiesel was confirmed by ${ }^{1} \mathrm{H}$ NMR spectrum, TGA and FTIR analysis. Elemental analysis shows the absence of sulfur and nitrogen which indicates eco-friendly biodiesel. TBHQ at $1000 \mathrm{ppm}$ has shown the highest induction time of $16.49 \mathrm{hr}$ at $110{ }^{\circ} \mathrm{C}$. This study indicates that MSO is a potential source of biodiesel.

\section{Acknowledgement}

The authors gratefully acknowledge Nasu Mia, Abdul Hamid and A.K.M. Abul Kalam, Technician, IFRD, Bangladesh Council of Scientific and Industrial Research (BCSIR) for providing technological support.

\section{References}

Agarwal AK, Das LM (2001), Biodiesel development and characterization for use as a fuel in compression ignition engines. Trans Am Soc Mech Eng, 123: $440-447$

Balat M, Balat H (2008), A critical review of bio-diesel as a vehicular fuel. Energy Conversion and Manage, Fuel: 1-15.
Canakci M, Van Gerpan J (1999), Biodiesel production via acid catalysis. Trans Am Soc Agric Eng, 42(5):12031210 .

Domingos AK, Saad EB, Vechiatto WWD, Wilhelm HM, Ramos LP ( 2007), The influence of BHA, BHT and TBHQ on the oxidation stability of soybean oil ethyl esters(biodiesel). Journal of the Brazilian Chemical Society, 18: 416-423.

Encinar JM, Gonzalez JF, Rodriquez JJ, Tejedor A (2002), Biodiesel production from vegetable oils: transesterification of Cynara cardunculus L. oil ethanol. Energy Fuels, 16: 443-450.

Joshi RM, Pegg MJ (2007), Flow properties of biodiesel fuel biends at low temperatures. Fuel, 86: 143-151.

Leung DYC, Xuan Wu, Leung MKH (2010), A review on biodiesel production using catalyzed transesterification. Appl Energy, 87: 1083-1095.

Majid MA, Rahman I.M.M, Shipar M.A.H, Uddin MH, Chowdhury R. (2004), Physico-Chemical Characterization, Antimicrobial Activity and Toxicity Analysis of Swietenia mahagoni Seed Oil. Int. J. Agri. Biol., 6(2): 350-354.

Monyem A, Van Gerpen JH (2001), The effect of biodiesel oxidation on engine performance and emissions. Biomass \& Bioenergy, 20: 317-325.

Morshed M, Ferdous K, Khan MR, Mazumder MSI, Islam MA, Uddin MdT (2011), Rubber seed oil as a potential source for biodiesel production in Bangladesh. Fuel, 90: $2981-2986$.

Ong, H C, Mahlia, T. M I, Masjuki, HH \& Norhasyima, RS (2011). Comparison of palm oil, Jatropha curcas and Calophyllum inophyllum for biodiesel: a review. Renewable and Sustainable Energy Reviews, 15(8): 3501-3515.

Pilar DM, Evaristo B, Franscisco JL, Martin M (2004), Optimization of alkali-catalyzed transesterification of brassica carinata oil for biodiesel production. Energy Fuels, 18: 77-83.

Recep A, Selim C, Huseyin SY (2001), The potential of using vegetable oil as fuel for diesel engines. Energy Conv Mgmt, 42: 529-538. 
Sahoo PK, Das LM, Babu MKG, Naik SN (2007), Biodiesel development from high acid value polanga seed oil and performance evaluation in a CI engine. Fuel, 86: 448454.

Sinha S, Agarwal AK, Garg S (2008), Biodiesel development from rice bran oil: Transesterification process optimization and fuel characterization. Energy Conversion and Management, 49: 1248-1257.

Sylvester O'Donnell, I. Demshemino, M. Yahaya, I. Nwadike and L.Okoro (2013), A review on the Spectroscopic Analyses of Biodiesel. European International Journal of Science and Technology, 2: 137-146.
Tao Y (1995), Operation of a cummins N14 diesel on biodiesel: performance, emissions and durability. National Biodiesel Board, Ortech Report No. 95-E11B004524.

$\mathrm{Xu}$ Li, Guanzhong Lu , Yanglong Guo, Yun Guo, Yanqin Wang, Zhigang Zhang, Xiaohui Liu, Yunsong Wang (2007), A novel solid superbase of $\mathrm{Eu}_{2} \mathrm{O}_{3} / \mathrm{Al}_{2} \mathrm{O}_{3}$ and its catalytic performance for the transesterification of soybean oil to biodiesel. Catalysis Communications, 8: 1969-1972.

Received: 23 June 2015; Revised: 29 June 2015; Accepted: 30 June 2015. 